Citation: P. Hayes (2020) Creating Opportunity from Crisis, Progress from Research: Redefining the Wine Sector. Wine Economics and Policy 9(1): 3-4. doi: $10.36253 /$ web-8333

Copyright: (c) 2020 P. Hayes. This is an open access, peer-reviewed article published by Firenze University Press (http://www.fupress.com/wep) and distributed under the terms of the Creative Commons Attribution License, which permits unrestricted use, distribution, and reproduction in any medium, provided the original author and source are credited.

Data Availability Statement: All relevant data are within the paper and its Supporting Information files.

Competing Interests: The Author(s) declare(s) no conflict of interest.

\section{Discussion \\ Creating Opportunity from Crisis, Progress from Research: Redefining the Wine Sector}

\author{
Peter Hayes AM $^{1}$ \\ Honorary President of OIV \\ E-mail: grapwine@senet.com.au
}

Change, for some, is reluctantly accepted, yet, for others, it's welcomed and embraced.

This decade shall likely entail even more changes in our world and the wine sector than has ever been experienced, requiring a significant reliance on the knowledge, experience, resilience and innovative capacity of colleagues, academic and professional in securing a sustainable and prosperous future.

Perhaps, in its own way, the transfer of this journal from hosting by Elsevier to the Florence University Press signifies a preparedness for timely adaptation to the pressures facing, in this case, the publication of peerreviewed research.

A decade on from the founding of this journal, and having been invited to contribute this editorial comment, I reviewed the editorial we prepared for the first issue; Editorial / Wine Economics and Policy 1 (2012) 87-88. It is evident that many of the issues noted at that time remain relevant, albeit now accompanied by additional emerging and important themes.

Back in 2012 the issues we identified spanned the gamut of economics, finance, business management and policy and identified several key issues which might now, a decade on, be considered even more relevant and topical. These issues include the drivers and facilitators of adaptation and innovation within the sector; adequacy and timeliness of data collection, analysis and interpretation, now much more broadly developed with "big data" and artificial intelligence; and the restructured and alternative distribution pathways, now reinforced by innovation in IT, e-commerce and social media.

Without ignoring the relatively recent and substantial development of China, the wine industry is a mature industry in much of the producing and

\footnotetext{
${ }^{1}$ Peter Hayes is WEP Business Editor, Honorary (former) President of the OIV and has other current roles; President, Lien de la Vigne/Vine Link; Presiding Member, Wine Australia Board Selection Committee; Member, Wine Australia Geographic Indications Committee; Independent Chairman, Almond Board of Australia. He has been an active promoter of R\&D, and professional development activity contributing to adaptation and innovation within the sector and now operates as an independent Wine Industry Strategist and Advisor with activity in Australia, the UK, China, and India.
} 
consuming world. Growth opportunity in such markets appears limited as do the prospects of new markets, notwithstanding the frequently expressed potential for such candidates as China and India.

Addressing the future of the wine world, what then might be some of the key themes warranting $R \& D$, adaptation and innovation to assist in securing a viable and prosperous sector?

First, the consumer: We observe and see commentary on the dramatic changes in consumer demographics, consumer preferences and behaviours, the influence of novel and evolving models of communication, and the role of competing products, services and experiences. Attention to the publication and promotion of insights, models and adaptive strategies to recruit and retain a rejuvenated and enduring consumer base and to frame the appropriate development of innovative wine and wine-based products should be highly valued.

Second, the supply or (preferably), the value chain: Although likely to be contested by some, the current supply or value-chain arrangements encourages excess supply in the interests of access to "cheap" supplies, fails to deliver reliable, predictable supply, poorly allocates risk and reward and imposes considerable stress on natural resources and social licence. Global economic and public health crises or conflicts, as arise from time to time, impose further uncertainty in securing inputs to the production process, visitation by tourists and in delivering products and services. This situation offers considerable challenges to both the wine sector and to others concerned with food security and resource use accountability. To retain and enhance legitimacy of trade in wine (and other foodstuffs), the industry shall require improved models of supply-demand balance, value allocation, food security and risk mitigation, along with development of transparent, credible resource -use accounting (perhaps a "resource -return quotient") and reporting systems, their validation and promotion, accompanied by policy development to facilitate their adoption.

Third, just what is "The Wine Industry"? Is it a supplier of commodity or product, cultural or lifestyle experience, hospitality or tourism destination or some combination thereof? A range of market and commercial factors in combination with economic policy, social and resource pressures shall likely see further diversification and specialisation in strands of wine-business and related activity. Considerable potential and value lie in describing, devising and validating alternative models to meet the pressures for commercial adoption and adaptation across the future decade.

In closing, there remains enormous potential for the academic research \& development community to engage with the professional sector for the benefit of each of the parties, the broader community and the environment. Assessment and reporting on effective models for such engagement, the related investment funding and evaluation of system and process improvements would be much welcomed. This should provide a solid foundation for adapting this journal, and assisting the industry itself, to meet forthcoming challenges and opportunities.

Since 4th March 2020, when I first drafted this discussion for the Journal, much has changed with whole societies severely disrupted, the wellbeing of individuals and families under considerable stress and national and international economies and trading in turmoil. The future of the many business enterprises and employment of many individuals within the sector is clearly threatened, as is the financial security and confidence of its consumers, and broader society; this prompts the question of what could and should be the nature, form and scale of the wine sector of the future?

My view is reinforced that $R \& D$, and its publication and promulgation, must actively adapt to better envisage, project, and analyse prospective scenarios, to inform future policy, planning and strategy at all levels. This shall demand better interaction and integration with, and recognition by, other elements of the sector and society, and is especially crucial given that under the anticipated economic conditions, financial support for R\&D is likely to be further constrained.

For all players to plan and secure their future relevance, legitimacy, efficiency, and effectiveness from which a prosperous future may be attained, demands a serious reorientation of focus.

A successful reorientation would create opportunity from crisis, greater progress from research, and would substantially contribute to redefining the wine sector, globally. 